\title{
Do not take a chance! We do not tell fortunes
}

\author{
Tatsuo Shimosawa $^{1}$
}

Received: 11 December 2021 / Accepted: 16 December 2021 / Published online: 14 January 2022

(c) The Author(s), under exclusive licence to The Japanese Society of Hypertension 2022

According to our recently published guideline [1], we choose first-line antihypertensives from among three major classes, thiazide diuretics, calcium channel blockers, and renin-angiotensin inhibitors, unless the patients have specific organ damage. By using these three classes of drugs, we target blood pressure. These three classes of drugs are supported by large amounts of clinical data showing that they effectively lower blood pressure and protect organs from hypertension. Nevertheless, we know that not all patients respond to these drugs equally; some are responsive to diuretics, and some are not. It is said that salt-sensitive individuals and those who are consuming a high-salt diet are more likely to respond to thiazide. It has been reported that plasma renin activity (PRA) can predict blood pressure responses to thiazide diuretics [2]. However, plasma renin activity varies depending on the sampling conditions. It is well known that upright posture increases PRA, and in clinical settings, it is difficult to standardize the postural status in outpatient phlebotomy labs [3]. Advancing age decreases PRA; therefore, the cutoff value of PRA should be set according to age. Females have lower PRA than males. In addition to these preanalytical factors, cryoactivation of PRA is an another important preanalytical factor. When the sampled blood is kept at low temperature, PRA increases. Once the plasma is separated, it should be frozen rapidly and kept frozen until analysis. PRA is also affected by analytical factors, such as $\mathrm{pH}$ and the abundance of angiotensinogen. Therefore, PRA is not yet recommended as a biomarker for thiazide usage.

To overcome these difficulties in using PRA as a marker for thiazide sensitivity, genetic analysis and liquid biopsy have been investigated. Some genetic markers for thiazide effectiveness $[4,5]$ have been reported, and in this issue of

Tatsuo Shimosawa

shimosawa-lab@iuhw.ac.jp

1 The Department of Clinical Laboratory, International University of Health and Welfare, Chiba, Japan
Hypertension Research, Huang et al. [6] successfully found candidate biomarkers for thiazide sensitivity in an Asian cohort. Their research reproduced the investigations in Caucasian and Black individuals [7, 8]. They claimed that sphingolipids can serve as a biomarker to predict thiazide sensitivity, and a possible mechanism is that those sphingolipids alter the ability of the drug to bind to NCC. We must pay attention to the interpretation of these studies. First, the observational period is substantially different between Huang6 and other studies [7, 8], 2 weeks and 9 weeks. The blood pressure-lowering effect of thiazide is biphasic, and in the early stage, thiazide decreases blood volume and lowers blood pressure; later, thiazide lowers vascular resistance rather than controlling blood volume [9]. The blood pressure-lowering effect of thiazide may differ between these two periods. In the early phase, when Huang's observations were conducted, thiazide mainly blocks NCC, and the interaction of sphingolipids and thiazides in terms of binding ability might explain the causeeffect relationship. Second, Shahin et al. [7] claimed that the sphingolipid level was determined genetically and that Huang6 did not evaluate the genetic background. Sphingolipid levels are regulated not only by genetic background but also by environmental factors such as inflammation [10]. Sphingolipid is degraded to ceramide by sphingomyelinase, which is activated under high inflammation conditions. I assume that patients with high inflammation might be resistant to thiazide after several weeks of treatment, which is possibly related to the effect of thiazide on the vasculature.

We often experience changes in responsiveness to drugs in the same patient. This is possibly due to changes in pharmacodynamics, such as drug metabolism, absorption, or distribution, as well as drug interactions. In addition to these drugs' per se effect, the pathophysiological condition of the patients should also be considered. For example, long-term use of thiazide activates the renin-angiotensin-aldosterone axis to lead to activation of pendrin at the collecting duct in the kidney to increase sodium reuptake and results in thiazide resistance [11]. We often use receptor antagonists, and 
these drug effects may be altered by the ligand level and the function of the receptor itself. This leads us to conclude that genetic backgrounds do not necessarily determine drug responsiveness, but environmental factors play pivotal roles. Using biomarkers to predict drug effects is very promising and needs more studies and more candidates in different clinical settings, and the data should be carefully evaluated.

\section{Compliance with ethical standards}

Conflict of interest The authors declare no competing interests.

Publisher's note Springer Nature remains neutral with regard to jurisdictional claims in published maps and institutional affiliations.

\section{References}

1. Umemura S, Arima H, Arima S, Asayama K, Dohi Y, Hirooka Y, et al. The Japanese Society of Hypertension Guidelines for the Management of Hypertension (JSH 2019). Hypertens Res. 2019;42:1235-481. https://doi.org/10.1038/s41440-019-0284-9.

2. Turner ST, Schwartz GL, Chapman AB, Beitelshees AL, Gums JG, Cooper-DeHoff RM, et al. Plasma renin activity predicts blood pressure responses to $\beta$-blocker and thiazide diuretic as monotherapy and add-on therapy for hypertension. Am J Hypertens. 2010;23:1014-22. https://doi.org/10.1038/ajh.2010.98.

3. Rutledge AC, Johnston A, Bailey D, Booth RA, Edmond P, Leung V, et al. Survey of renin and aldosterone testing practices by Ontario laboratories-providing insight into best practices. Pract Lab Med. 2021;25:e00229 https://doi.org/10.1016/j.plabm. 2021.e00229.
4. Matayoshi T, Kamide K, Takiuchi S, Yoshii M, Miwa Y, Takami $\mathrm{Y}$, et al. The thiazide-sensitive $\mathrm{Na}(+)-\mathrm{Cl}(-)$ cotransporter gene, C1784T, and adrenergic receptor-beta3 gene, T727C, may be gene polymorphisms susceptible to the antihypertensive effect of thiazide diuretics. Hypertens Res. 2004;27:821-33. https://doi.org/10. 1291/hypres.27.821.

5. Huang CC, Chung CM, Hung SI, Leu HB, Wu TC, Huang PH, et al. Genetic variation in renin predicts the effects of thiazide diuretics. Eur J Clin Invest. 2011;41:828-35. https://doi.org/10. 1111/j.1365-2362.2011.02472.x. Epub 2011 Jan 25.

6. C-C Huang, Y-L Huang, C-H Lin, J-W Chen. Plasma metabolomic profiles associated with hypertension and blood pressure in response to thiazide diuretics. Hypertens Res. https://doi.org/10. 1038/s41440-021-00825-9.

7. Shahin MH, Gong Y, Frye RF, Rotroff DM, Beitelshees AL, Baillie RA, et al. Sphingolipid metabolic pathway impacts thiazide diuretics blood pressure response: insights from genomics, metabolomics, and lipidomics. J Am Heart Assoc. 2017;7: e006656 https://doi.org/10.1161/JAHA.117.006656.

8. Mehanna M, McDonough CW, Smith SM, Gong Y, Gums JG, Chapman $\mathrm{AB}$, et al. Metabolomics signature of plasma renin activity and linkage with blood pressure response to beta blockers and thiazide diuretics in hypertensive European American patients. Metabolites. 2021;11:645 https://doi.org/10.3390/metabo11090645.

9. Shah S, Khatri I, Freis ED. Mechanism of antihypertensive effect of thiazide diuretics. Am Heart J 1978;95:611-8. https://doi.org/ 10.1016/0002-8703(78)90303-4.

10. Nikolova-Karakashian M, Karakashian A, Rutkute K. Role of neutral sphingomyelinases in aging and inflammation. Subcell Biochem. 2008;49:469-86. https://doi.org/10.1007/978-1-4020-8831-5_18.

11. Ayuzawa N, Nishimoto M, Ueda K, Hirohama D, Kawarazaki $\mathrm{W}$, Shimosawa $\mathrm{T}$, et al. Two mineralocorticoid receptormediated mechanisms of pendrin activation in distal nephrons. J Am Soc Nephrol 2020;31:748-64. https://doi.org/10.1681/ ASN.2019080804. Epub 2020 Feb 7. 